\title{
Response Surface Methodology Approach to the Optimization of Potato (Solanum tuberosum) Tuber Yield Using Second-Order Rotatable Design
}

\author{
Koech $\mathrm{JK}^{1 *}$, Mutiso MJ ${ }^{2}$ and Koskei $\mathrm{JK}^{2}$
}

${ }^{1}$ Department of Mathematics and Computer Science, University of Eldoret, Kenya

${ }^{2}$ Department of Statistics and Computer Science, Moi University, Eldoret, Kenya

\begin{abstract}
One of the major concerns among developing countries in recent decades is the effect of declining food security with ever-growing population. Hence, the importance of adopting cost effective farming methods has led to the development of various statistical methods to alleviate food insecurity. Among these methods, CCD has gained significant attention to its application in agriculture. In this paper, the response surface methodology (RSM) was applied in order to determine the effects of the factors potassium $(K)$, nitrogen $(N)$ and phosphorus $(P)$ on the yield of potato tuber. The predicted values for the yield of potato tuber by the response functions were in a very close agreement with experimental data $\left(R^{2}=90 \%\right)$. The second-order model was developed by solving the parameters of the regression equation using the method of least squares. The optimal combinations of the factors potassium $(K)$, nitrogen $(N)$ and phosphorus $(P)$ with yield as the response of interest were determined by analyzing the 3D response surface plots and using the method of steepest ascent. Using ridge analysis method which corresponds to the method of steepest ascent, the optimal yield of potato tuber was estimated to be $29.26 \mathrm{tha}^{-1}$ which is much higher than the current national target of $14 \mathrm{th} \mathrm{h}^{-1}$ with optimum factor levels being $K=35.36 \mathrm{~kg} \mathrm{~K}_{2} \mathrm{O} \mathrm{ha} a^{-1}, N=78.71 \mathrm{Kg} \mathrm{N} \mathrm{ha}^{-1}$ and $P=160.69 \mathrm{Kg} P=160.69 \mathrm{~kg}_{2} \mathrm{O}_{5} h^{-1}$, respectively. Nitrogen and phosphorous had a significant positive linear effects on the potato tuber yield. Based on the results, it can be concluded that the response surface methodology is a suitable approach for determining the optimal conditions of the selected fertilizer types.
\end{abstract}

Keywords: Developing countries; Food security; Factors; CCD; Optimal yield; RSM; Steepest ascent

\section{Introduction}

Potato consumption has increased in the developing world, and over the last decade, world potato production has increased at an annual average rate of 4.5 percent. Furthermore; Kirkman [1] has estimated that global consumption in processed form will increase from $13 \%$ of total food use in 2002 to nearly $18 \%$ by 2020 . Potato is a high nitrogen $(\mathrm{N})$, phosphorus $(\mathrm{P})$ and potassium $(\mathrm{K})$-demanding crop. Deficiency of any or combinations of these nutrients can result in retarded growth or complete crop failure under severe cases [2]. Fertilizer type and application rates for potato have not been extensively studied in the rain-fed areas of Western Kenya. The ever increasing demand for potato in the country is due to population growth, urbanization, tourism and export of processed products (MoA, 2005). Potato remains as an important food and cash crop in Eastern and Central Africa, playing a major role in national food security and nutrition, poverty alleviation and income generation, and; provides employment in the production, processing and marketing subsectors.

From a global perspective, its productivity is low in areas under rainfed farming systems [3,4]. Several factors have been attributed for the low yields which include low or inappropriate application of inputs like clean seeds, fertilizers and control of the major potato diseases [5]. RSM emerged in the 1950s [6] within the context of Chemical Engineering in an attempt to construct empirical models able to find useful statistical relationships between all the variables making up an industrial system. Response surface methodology (RSM) has been a useful statistical technique for modeling and analyzing situations in which the response of interest is influenced by several variables and the objective is to optimize this response [7].

In recent years, response surface methodology has been applied in many different fields of research for optimization [8]. Many agricultural experiments involve responses to the explanatory variables which are binary or counts in nature and which can thus be modelled within the generalized linear model framework [9]. Factorial designs have widely been used in experiments involving several factors where the interest is to investigate the joint effects of the factors on a response variable. Such an experiment allows the investigator to study the effect of each factor on the response variable, as well as the effects of interactions between factors on the response variable [10]. In this paper, the effects of the factors such as potassium $(\mathrm{K})$, nitrogen $(\mathrm{N})$ and phosphorus $(\mathrm{P})$ on the yield of potato tuber was investigated with application of the secondorder model.

\section{Materials and Methods}

\section{Experimental design}

$2^{3}$-factorial central composite designs $\left(2^{3}\right.$-FCCD) were carried out in order to identify optimum parameter levels of fertilizer type for potato tuber yield. The parameters (or independent variables) that were investigated are: potassium (K), nitrogen (urea 46\%) and phosphorus (TSP 46\%). The FCCD had a total of 16 experimental trials that included eight trials for factorial points, six trials for axial points and two trials for the central points. The experiment was replicated three times to produce 48 experimental units.

*Corresponding author: Koech JK, Department of Mathematics and Computer Science, University of Eldoret, Kenya, Tel: +254 724073 390; E-mail: koechjulius2005@yahoo.com

Received February 19, 2017; Accepted May 20, 2017; Published May 31, 2017

Citation: Koech JK, Mutiso MJ, Koskei JK (2017) Response Surface Methodology Approach to the Optimization of Potato (Solanum tuberosum) Tuber Yield Using Second-Order Rotatable Design. J Biom Biostat 8: 351. doi: 10.4172/21556180.1000351

Copyright: @ 2017 Koech JK, et al. This is an open-access article distributed unde the terms of the Creative Commons Attribution License, which permits unrestricted use, distribution, and reproduction in any medium, provided the original author and source are credited. 
For statistical calculations, the variables $X_{i}$ was coded as $x_{i}$ as shown in the equation (1) below

$$
x_{i}=\frac{X_{i}-X_{0 i}}{\Delta X_{i}}, i=1,2,3, \ldots, k,
$$

where $x_{\mathrm{i}}$ is the dimensionless value of an independent variable, $X_{i}$ is the real value of an independent variable, $X_{0 i}$ is the real value of the independent variable at the centre point, and $\Delta X_{i}$ is the step change. In coded variables, the scale of the design variables are changed in such a way that the low and high value correspond to -1 and +1 , respectively. The independent variables and their coded levels are shown in Table 1 below. The levels of each factor were established according to literature information by International Fertilizer Industry Association.

\section{Experimental layout, treatments, design and procedures}

Potatoes were planted in Western Kenya at one of the farms which is $15 \mathrm{~km}$ East of Eldoret Town between $15^{\text {th }}$ March and $1^{\text {st }}$ April 2016 after which seed potato tubers were left to grow for a period of three months (90 days). Fertilizer treatments applied at planting were broadcasted over the furrows.

The experiment was laid out using a randomized complete block design with three replicates for each treatment. Each experimental plot measured $4.0 \mathrm{~m} \times 4.0 \mathrm{~m}$ and consisted of 5 rows of 18 tubers each. The plant spacing was $0.25 \mathrm{~m} \times 0.75 \mathrm{~m}$ within and between the rows, respectively. The total number of experimental plots was 48 . A distance of $1 \mathrm{~m}$ was maintained between the blocks and $50 \mathrm{~cm}$ within the replicates. At harvesting, tuber weight was recorded and this gave average total yield per plot. The treatments consisted of potassium $\left(60 \% K_{2} \mathrm{o}\right)$ with rates $\left(32,48.5\right.$ and $\left.65 \mathrm{~kg} K_{2} \mathrm{o} \mathrm{ha} a^{-1}\right)$ and nitrogen $(\mathrm{N})$ supplied as Urea $(46 \% \mathrm{~N})$ at three rates $\left(40,60\right.$ and $\left.80 \mathrm{~kg} \mathrm{~N} \mathrm{ha}^{-1}\right)$, with all fertilizers being applied at planting season. Phosphorus $(\mathrm{P})$ was also supplied at planting time as triple super phosphate $\left(46 \% P_{2} o_{5}\right)$ at three rates namely $\left(77,116\right.$ and $\left.155 \mathrm{Kg} P_{2} o_{5} h a^{-1}\right)$, respectively. The experimental range and level of the above variables are given in Table 2 below.

Transformation of coded variable/factor $\left(x_{\mathrm{i}}\right)$ levels to uncoded/ original variables were obtained using the following equations

$$
X_{1}=16.5 x_{1}+48.5 ; X_{2}=20 x_{2}+60 ; X_{3}=39 x_{3}+116
$$

The second order equation to predict the optimal condition can be expressed as shown below;

$$
Y=b_{0}+\sum_{i=1}^{k} b_{i} x_{i}+\sum_{i=1}^{k} \sum_{j=2}^{k} b_{j} x_{i} x_{j}+\sum_{i=1}^{k} b_{i} x_{i}^{2}+\varepsilon, i \neq j
$$

Where $Y$ is the response variable, whereas $x_{\mathrm{i}}$ is representing the explanatory or the independent variables and $\varepsilon$ is the random error. The $\beta$ coefficients, which should be determined in the second-order model, are obtained by the least square method. In general, equation (3) can be written in matrix form as

$$
Y=b X+\varepsilon
$$

where $\mathrm{Y}$ is defined to be a matrix of measured response values, $\mathrm{X}$ to be a matrix of independent variables and $\varepsilon$ consist of the error term, respectively. The solution of equation (4) can be obtained by the matrix approach as shown in equation (5) below,

$$
\mathrm{b}=\left(X^{T} \mathrm{X}\right)^{-1} X^{T} \mathrm{Y}
$$

Where $X^{T}$ is the transpose of the matrix $\mathrm{X}$ and $\left(X^{T} \mathrm{X}\right)^{-1}$ is the inverse of the matrix $X^{T} X$. The experimental data were analyzed using $\mathrm{R}$ and SAS version 9.2 statistical software. The validity of the predicted model was verified by use analysis of variance (ANOVA). The second-order model quality was also assessed by using the correlation factor $\left(\mathrm{R}^{2}\right)$. Finally, the optimal combinations of the factors were obtained by analyzing the $3 \mathrm{D}$ response surface curves and with application of ridge analysis method.

\section{Results and Discussion}

Table 1 below shows that the highest yield of potato tuber attained

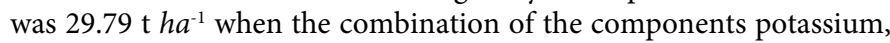
nitrogen, and phosphorous were at 32, 80, and $155 \mathrm{Kg} \mathrm{ha}^{-1}$, respectively (Run 2). This yield is particularly higher than what has been obtained recently in the selected countries of Eastern Africa, Central Africa and Southern Africa where average potato tuber yield was found to be below $13 \mathrm{t} h a^{-1}$ while in Kenya was approximately $23 \mathrm{t} \mathrm{ha^{-1 }}$ [11]. Also, the lowest yield was at $18.96 \mathrm{t} h \mathrm{a}^{-1}$, which was achieved when potassium, nitrogen, and phosphorus components were at 32, 40, and $77 \mathrm{Kg} \mathrm{ha}^{-1}$, respectively (Table 2 ).

\section{Effect of the type and level of fertilizer applied on the yield of potato tuber}

This section presents exploratory analysis of factors that are known to influence yield of potato tuber. This is illustrated using correlation analysis, box plots and regression analysis with application of the second-order model.

Figure 1 below show that there was a weak negative correlation between yield of potato tuber and potassium as a factor $\left(r=-0.061_{r s}\right.$, $p$-value $=0.821$ ). This finding is in disagreement with other studies conducted elsewhere which have shown potassium to increase yield of potato tuber [12]. However, a slight positive association was observed for the effect of nitrogen on the yield $\left(\mathrm{r}=0.261_{\mathrm{rs}}, p\right.$-value $\left.=0.321\right)$, with higher levels of the factor having increased yield of potato tuber. It is also evident that there was a strong significant positive correlation between yield and the factor phosphorus $\left(\mathrm{r}=-0.749_{\mathrm{s}}, p\right.$-value $\left.=0.0008\right)$.

The present study is in agreement with the findings of Rosen and Bierman [13], who reported that the interaction effect of nitrogen and phosphorus affected average tuber number per hill of potato plants. The increase in tuber numbers per hill for potato in response to increased application of nitrogen and phosphorus is also consistent with the results of Jenkins and Ali [14]. Similarly, other researchers have reported increased rates of phosphorous to cause improved yield of potato tuber [15]. The reason for this is that phosphorus contributes

\begin{tabular}{|c|c|c|c|c|c|c|}
\hline \multirow[t]{2}{*}{ Factor } & \multirow[b]{2}{*}{ Symbol $\left(X_{i}\right)$} & \multicolumn{5}{|c|}{ Coded factor level $\left(x_{i}\right)$} \\
\hline & & $-1.68(\alpha)$ & -1 & 0 & 1 & $1.68(\alpha)$ \\
\hline Potassium(K) & $\mathrm{X}_{1}$ & 20.8 & 32 & 48.5 & 65 & 76.2 \\
\hline Nitrogen $(\mathrm{N})$ & $\mathrm{X}_{2}$ & 26.4 & 40 & 60 & 80 & 93.6 \\
\hline Phosphorus (P) & $\mathrm{X}_{3}$ & 50.5 & 77 & 116 & 155 & 181.5 \\
\hline
\end{tabular}
to early development of the crop, early tuberization and thus increasing the number of tubers per plant.

From Figure 2 below, it is clear that application of $48.5 \mathrm{~kg}$ of potassium results in better yield than application of $65 \mathrm{~kg}$ per hectare.

Table 1: Assigned levels of fertilizer to be used in CCD for $k=3$. 
Citation: Koech JK, Mutiso MJ, Koskei JK (2017) Response Surface Methodology Approach to the Optimization of Potato (Solanum tuberosum) Tuber Yield Using Second-Order Rotatable Design. J Biom Biostat 8: 351. doi: 10.4172/2155-6180.1000351

Page 3 of 6

\begin{tabular}{|c|c|c|c|c|c|c|}
\hline \multirow[t]{2}{*}{ Run } & \multirow{2}{*}{$x_{1}$} & \multirow[t]{2}{*}{$x_{2}$} & \multirow[t]{2}{*}{$x_{3}$} & \multicolumn{2}{|c|}{ Mean yield(t/ha) } & \multirow[b]{2}{*}{$\begin{array}{c}\text { Deviation of Experiment and } \\
\text { Predicted } \%\end{array}$} \\
\hline & & & & Observed & Predicted & \\
\hline 1 & 1 & 1 & 1 & 25.42 & 24.897 & 2.06 \\
\hline 2 & -1 & 1 & 1 & 29.79 & 29.408 & 1.28 \\
\hline 3 & 1 & -1 & 1 & 20.83 & 21.650 & -3.94 \\
\hline 4 & -1 & -1 & 1 & 24.79 & 24.916 & -0.51 \\
\hline 5 & 1 & 1 & -1 & 21.46 & 21.923 & -2.16 \\
\hline 6 & -1 & 1 & -1 & 20.42 & 20.190 & 1.13 \\
\hline 7 & 1 & -1 & -1 & 22.08 & 23.052 & -4.40 \\
\hline 8 & -1 & -1 & -1 & 18.96 & 20.073 & -5.87 \\
\hline 9 & -1.68 & 0 & 0 & 23.96 & 23.871 & 0.37 \\
\hline 10 & 1.68 & 0 & 0 & 23.33 & 22.583 & 3.20 \\
\hline 11 & 0 & -1.68 & 0 & 24.17 & 22.650 & 6.29 \\
\hline 12 & 0 & 1.68 & 0 & 24.79 & 25.475 & -2.76 \\
\hline 13 & 0 & 0 & -1.68 & 20.21 & 19.114 & 5.42 \\
\hline 14 & 0 & 0 & 1.68 & 25.42 & 25.680 & -1.03 \\
\hline 15 & 0 & 0 & 0 & 23.75 & 22.674 & 4.53 \\
\hline 16 & 0 & 0 & 0 & 21.45 & 22.674 & -5.71 \\
\hline
\end{tabular}

Table 2: Design matrix of centered central composite design (CCD) for yield of potato tuber.
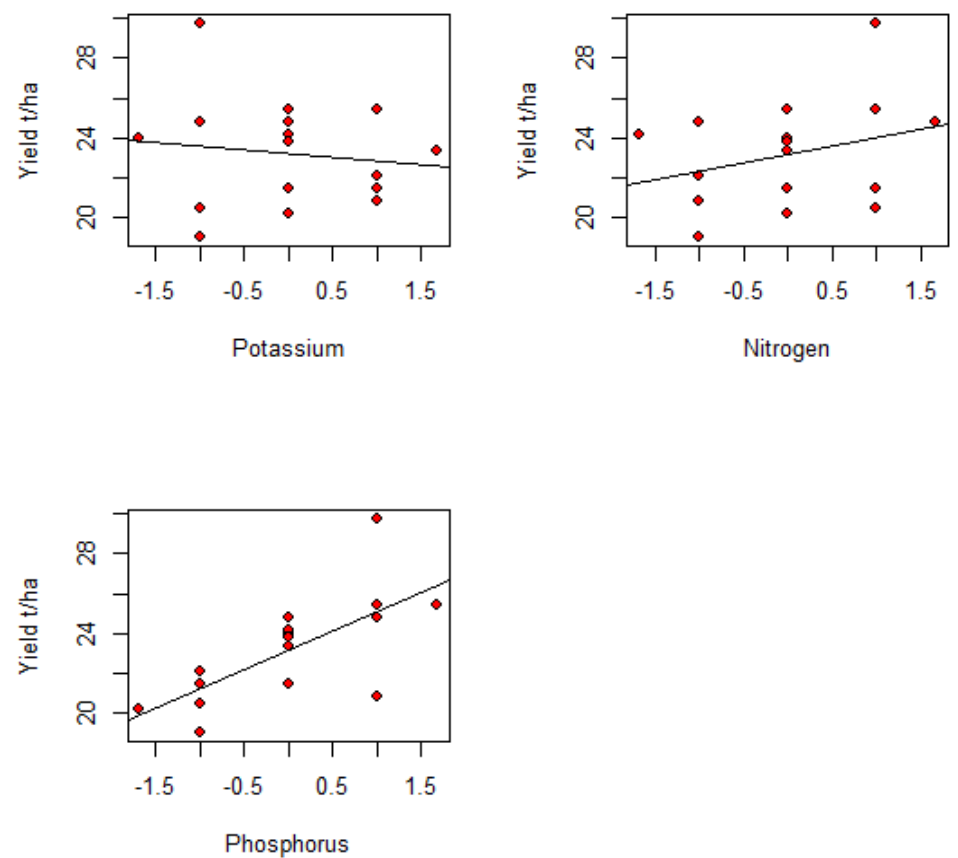

Figure 1: Correlation analysis of potato tuber yield with potassium, nitrogen and phosphorous as factors of interest, (ns=not significant), (s=significant).

However, there is no clear trend on the effects of different levels of potassium on the yield of potato tuber. On the other hand, potassium fertilizer application may not necessarily increase yield but can be useful as it makes potato plants adapt to the environmental stresses which leads to increased resistance of potato to some pests [16].

In Figure 3, increasing application of nitrogen fertilizer resulted in higher yield up to a certain level when compared to lower factor levels of nitrogen [17]. However, over-use of Nitrogen fertilizer has been established by other researchers elsewhere to cause a reduction in the yield of potato tuber [18] and this is consistent with the results of this study.

\section{Analysis of 3D response surfaces}

The $3 \mathrm{D}$ response surface plots were employed to evaluate the effect of independent variables on the yield of potato tuber. This was done by varying two variables within the experimental range under investigation and holding the other variable at its central level (0 level). The relationship between independent and dependent variables was graphically represented by $3 \mathrm{D}$ response surfaces as shown in Figures 4-7, respectively. Figure 5 show the 3D response surface plot for the effect of potassium $\left(x_{1}\right)$ and nitrogen $\left(x_{2}\right)$ on the yield of the potato tuber. It can be observed that increasing nitrogen similarly raised the yield of potato tuber while on the other hand increasing potassium decreased yield significantly. The increase of potato tuber yield due to nitrogen may be favored by the fact that nitrogen application increases potato plant density, hence resulting in higher potato tuber yield [19]. Similar findings were also reported by Arap Koskei [20] who revealed that potato tuber yield per unit area was increased with increasing nitrogen fertilizer up to a suitable level. 


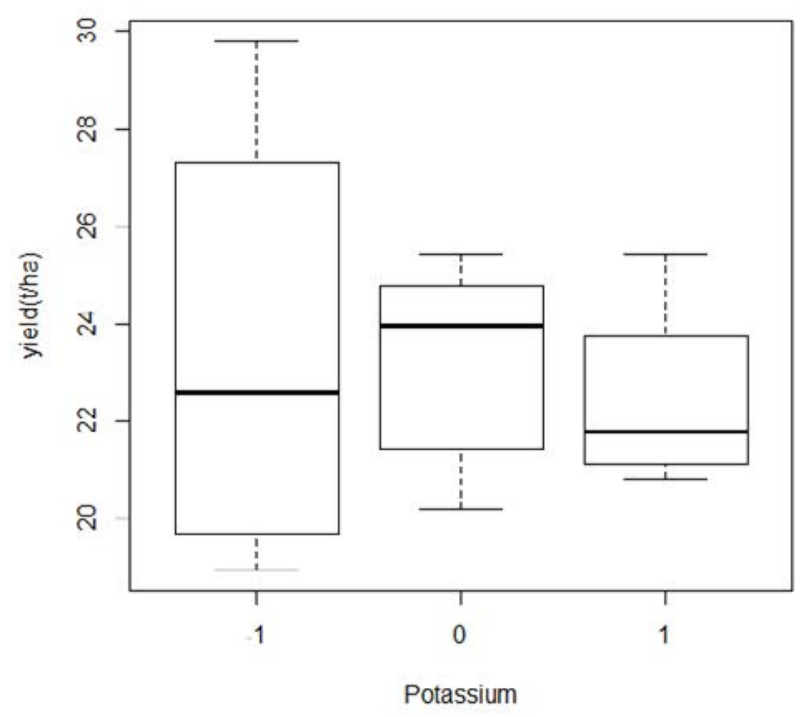

Figure 2: Box Plot of potato tuber yield per ha (in tons) versus potassium.

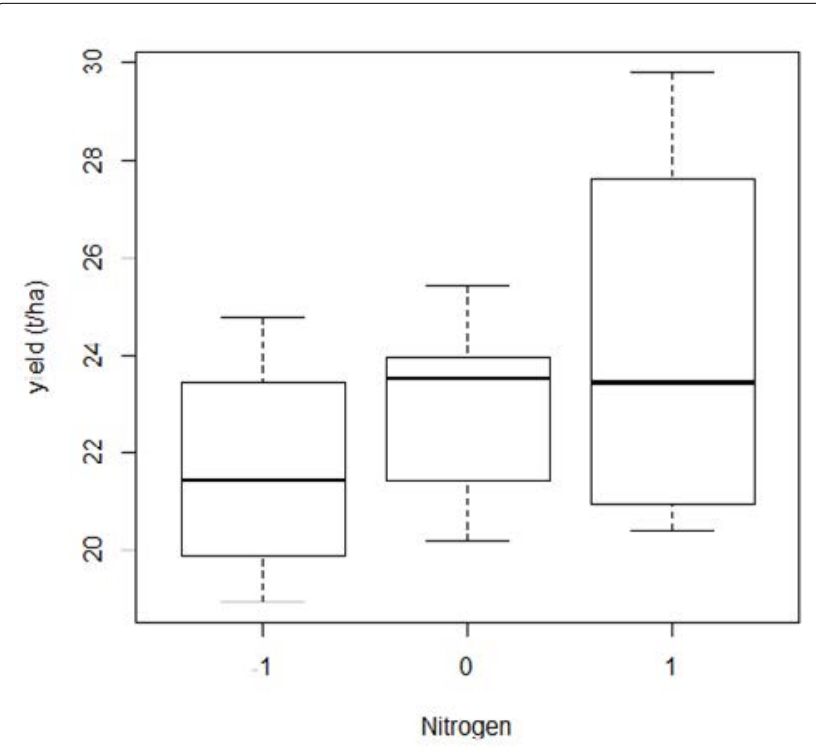

Figure 3: Box Plot of potato tuber yield per ha (in tons) versus Nitrogen.

Figure 6 demonstrates the interaction between potassium $\left(x_{1}\right)$ and phosphorous $\left(x_{3}\right)$ on the potato tuber yield. It was found out that increasing potassium to near $60 \mathrm{~kg} \mathrm{ha}{ }^{-1}$ improved the yield of potato tuber considerably. However, when the potassium level reached over $60 \mathrm{~kg} \mathrm{ha} \mathrm{a}^{-1}$, there was a gradual decline in the yield of potato tuber, while an increase in phosphorus showed a significant positive effect on the yield of potato tuber. The possible explanation for this result is that rising levels of phosphorous equally increases the number of potato tubers hence improving overall yield [15].

Figure 7 illustrates the effect of nitrogen $\left(x_{2}\right)$ and phosphorous $\left(x_{3}\right)$ on the yield of potato tuber. It was observed that when potassium $\left(x_{1}\right)$ was fixed at 0 level, yield of potato tuber increased to maximum when nitrogen was increased to a value of approximately $60 \mathrm{~kg} \mathrm{ha} a^{-1}$, while equally an increase in the level of phosphorous raised the yield of potato tuber.

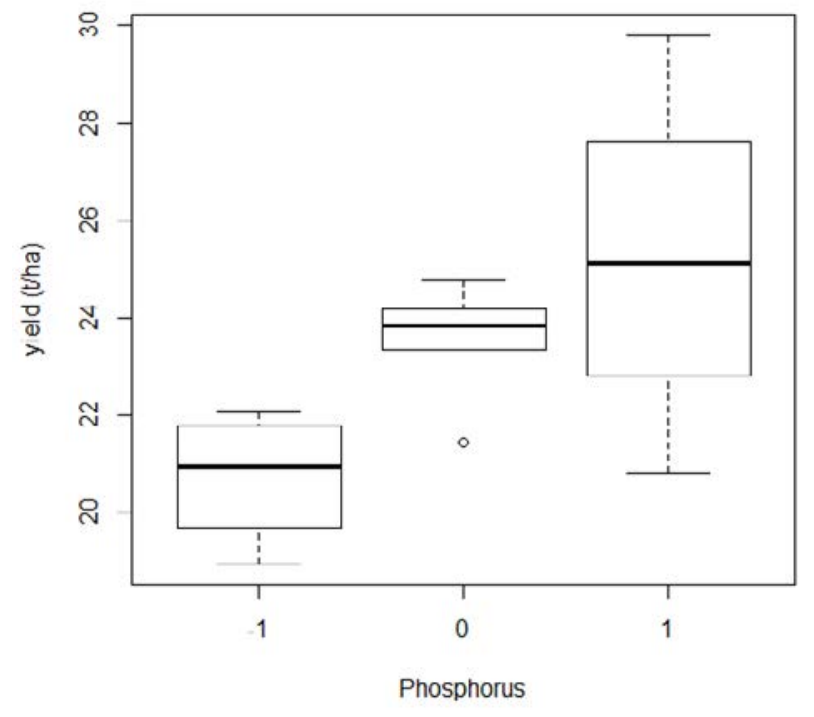

Figure 4: Box Plot of potato tuber yield per ha (in tons) versus Phosphorus.

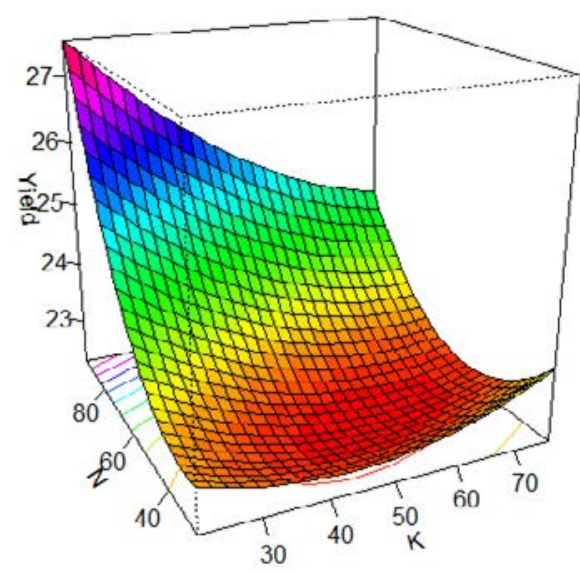

Slice at $\mathrm{P}=116$

Figure 5: Response surface plot showing the effect of potassium and nitrogen on the potato tuber yield.

\section{Estimating regression parameters by method of least squares using second-order.model}

This section presents experimental estimation of the parameters in the model for purposes of fitting our second-order model using equation (3) where data on the yield of potato tuber was considered as the response variable of interest and the factors potassium $\left(x_{1}\right)$, nitrogen $\left(x_{2}\right)$ and phosphorous $\left(x_{3}\right)$ were the independent variables [21-23]. Response surface methodology (RSM) was adopted for developing model for yield of potato tuber. The regression coefficients and significance levels of the model representing potato tuber yield is shown in Table 3 below. It is evident from Table 3 that the model terms $x_{3}$ and $x_{1} x_{3}$ were significant at $(\mathrm{P}<0.05)$ while the terms $x_{2}$ and $x_{2} x_{3}$ remained significant at $(\mathrm{P}<0.10)$. Regression analysis of the experimental data (Table 3$)$ showed that nitrogen $\left(x_{2}\right)$ and phosphorous $\left(x_{3}\right)$ had significant positive linear effects on the potato tuber yield. Out of the three parameters, 
Citation: Koech JK, Mutiso MJ, Koskei JK (2017) Response Surface Methodology Approach to the Optimization of Potato (Solanum tuberosum) Tuber Yield Using Second-Order Rotatable Design. J Biom Biostat 8: 351. doi: 10.4172/2155-6180.1000351

Page 5 of 6

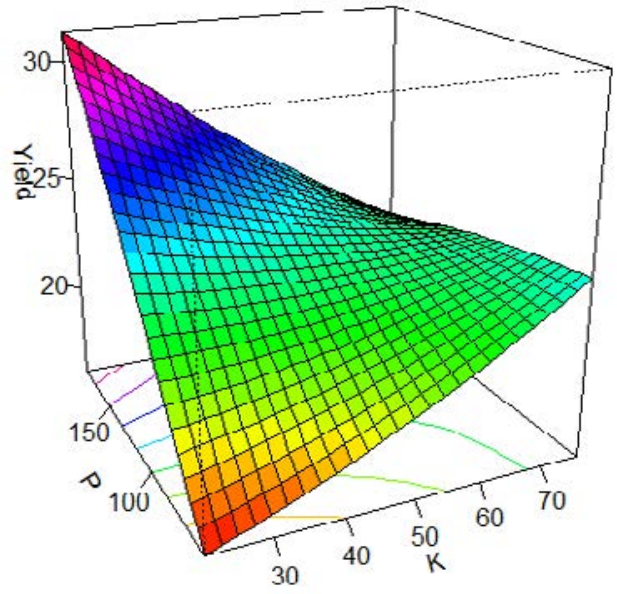

Slice at $\mathrm{N}=60$

Figure 6: Response surface plot showing the effect of Potassium and Phosphorous on the potato tuber yield.

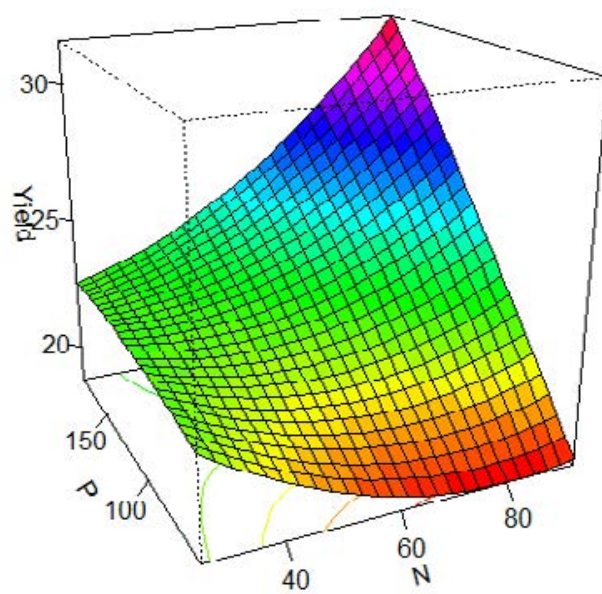

Slice at $\mathrm{K}=48.5$

Figure 7: Response surface plot showing the effect of nitrogen and phosphorous on the potato tuber yield.

phosphorous was found to have the highest contribution on the potato tuber yield with the highest linear positive effect $\left(\beta_{3}=1.954\right.$, $p=0.0017)$, followed by nitrogen and potassium $\left(\beta_{2}=0.841, p=0.0601\right)$ indicated a negative linear effect. Interaction of the factors, potassium and phosphorous $x_{1} x_{3}$ showed a strong significant negative effect on the potato tuber yield indicating that yield decreased as the levels of these factors decreased, while the interaction of the factors nitrogen and phosphorous $\left(x_{2} x_{3}\right)$ showed a positive significant effect at $10 \%$ level of significance indicating that potato tuber yield was higher as the levels of the factors also increased above certain values [24,25]. This finding is consistent with the study conducted by other researchers using second-order polynomial model elsewhere where the interaction between nitrogen and phosphorous $\left(x_{2} x_{3}\right)$ was shown to be significantly associated with increased potato tuber yield. Table 3 also indicates that the quadratic terms between all factors were not significant when yield was considered as the response of interest.

In Table 4, results of the analysis of variance was performed to evaluate the lack of fit and the significance of the linear, quadratic and interaction effects of the factors influencing the yield of potato tuber. The ANOVA results indicated a good model fit with the correlation coefficient $\left(\mathrm{R}^{2}\right)$ value of 0.90 for yield of potato tuber [26]. These can explain $90 \%$ of the variability in the calculated models. The statistical analysis gave high significant level, attesting the goodness of fit of the model in case of the yield $(\mathrm{p}=0.02199)$. The results obtained showed that the models could work well for the prediction of the three factors studied while using yield of the potato tuber as response variable of interest. It is clear from Table 5 below that using ridge analysis the optimal yield for potato tuber was $29.26 \mathrm{tha^{-1 }}$.

\begin{tabular}{|l|c|c|c|c|}
\hline Parameters & Coefficients & Standard Error & $\mathbf{t}$ Value & $\mathbf{P r}>|\mathbf{t}|$ \\
\hline Intercept & 22.674223 & 0.947011 & 23.94 & $<.0001^{\text {** }}$ \\
\hline$x_{1}$ & -0.383179 & 0.363709 & -1.05 & 0.3327 \\
\hline$X_{2}$ & 0.840731 & 0.363709 & 2.31 & $0.0601^{*}$ \\
\hline$X_{3}$ & 1.954063 & 0.363709 & 5.37 & $0.0017^{\star \star *}$ \\
\hline$x_{1}{ }^{2}$ & 0.195881 & 0.441940 & 0.44 & 0.6731 \\
\hline$x_{1} x_{2}$ & -0.311250 & 0.474999 & -0.66 & 0.5366 \\
\hline$x_{2}{ }^{2}$ & 0.491728 & 0.441940 & 1.11 & 0.3084 \\
\hline$x_{1} x_{3}$ & -1.561250 & 0.474999 & -3.29 & $0.0167^{\star *}$ \\
\hline$X_{2} x_{3}$ & 1.093750 & 0.474999 & 2.30 & $0.0609^{*}$ \\
\hline$x_{3}{ }^{2}$ & -0.098195 & 0.441940 & -0.22 & 0.8315 \\
\hline
\end{tabular}

Table 3: Estimated regression model of relationship between response variable (yield of Potato tuber) and independent variables $\left(x_{1}, x_{2}, x_{3}\right)$.

\begin{tabular}{|l|c|c|c|c|c|}
\hline Regression & DF & SS & MS & F Value & Pr > F \\
\hline Linear & 3 & 63.748730 & 0.5915 & 11.77 & $\mathbf{0 . 0 0 6 3}$ \\
\hline Quadratic & 3 & 3.353914 & 0.0311 & 0.62 & 0.6276 \\
\hline Cross-product & 3 & 29.845338 & 0.2769 & 5.51 & $\mathbf{0 . 0 3 6 9}$ \\
\hline Residuals & 6 & 10.830 & 1.805 & & \\
\hline Lack of fit & 5 & 8.185 & 1.637 & 0.6189 & 0.7404 \\
\hline Pure error & 1 & 2.645 & 2.645 & & \\
\hline Total error & 6 & 10.830 & 1.8050 & & \\
\hline
\end{tabular}

Notes: DF, degree of freedom; SS, sum of squares; MS, mean square.

Table 4: Analysis of variance for the fitted quadratic polynomial model for optimization of potato tuber yield.

\begin{tabular}{|c|c|c|c|c|c|}
\hline \multicolumn{8}{|c}{ Estimated Ridge of Maximum Response for Yield } \\
\hline Coded & Estimated & Standard & \multicolumn{3}{|c|}{ Uncoded Factor Values } \\
\cline { 4 - 6 } Radius & Response & Error & $\boldsymbol{x}_{\mathbf{1}}$ & $\boldsymbol{x}_{\mathbf{2}}$ & $\boldsymbol{x}_{\mathbf{3}}$ \\
\hline 0.0 & 22.674223 & 0.947011 & 0 & 0 & 0 \\
\hline 0.1 & 23.058842 & 0.939904 & -0.044770 & 0.074973 & 0.143523 \\
\hline 0.2 & 23.494885 & 0.919270 & -0.109712 & 0.161933 & 0.273198 \\
\hline 0.3 & 23.989748 & 0.887317 & -0.185185 & 0.254385 & 0.393714 \\
\hline 0.4 & 24.546929 & 0.848272 & -0.266428 & 0.349489 & 0.508387 \\
\hline 0.5 & 25.168209 & 0.809201 & -0.351084 & 0.445983 & 0.619224 \\
\hline 0.6 & 25.854568 & 0.780916 & -0.437903 & 0.543261 & 0.727443 \\
\hline 0.7 & 26.606588 & 0.777907 & -0.526171 & 0.641008 & 0.833804 \\
\hline 0.8 & 27.424633 & 0.815455 & -0.615457 & 0.739052 & 0.938803 \\
\hline 0.9 & 28.308944 & 0.904030 & -0.705484 & 0.837291 & 1.042775 \\
\hline 1.0 & $\mathbf{2 9 . 2 5 9 6 8 5}$ & 1.045819 & $-\mathbf{0 . 7 9 6 0 6 6}$ & $\mathbf{0 . 9 3 5 6 6 2}$ & $\mathbf{1 . 1 4 5 9 5 6}$ \\
\hline
\end{tabular}

$x_{1}$ : Potassium; $x_{2}$ : Nitrogen; $x_{3}$ : Phosphorous.

Table 5: Optimal yield of potato tuber using Ridge analysis. 
Citation: Koech JK, Mutiso MJ, Koskei JK (2017) Response Surface Methodology Approach to the Optimization of Potato (Solanum tuberosum) Tuber Yield Using Second-Order Rotatable Design. J Biom Biostat 8: 351. doi: 10.4172/2155-6180.1000351

\section{Conclusion}

This study used RSM and CCD to evaluate the effects of potassium, nitrogen and phosphorus on the yield of potato tuber. Based on the developed models, it was found that increased application of nitrogen and phosphorous was accompanied by an increase in the yield of potato tuber. However, the effect of potassium showed a negative effect on the yield of potato tuber and this maybe as a result of potassium being identified as a water retention factor. The yield of potato tuber showed both a positive linear and cross-product behaviour by nitrogen and phosphorus respectively. The application of response surface methodology combined with the CCD can be used as effective methods for investigating the effects of potassium, nitrogen and phosphorus on the yield of potato tuber. The factors considered in this study are important in influencing yield of potato tuber and can be adopted by both small and large-scale farmers in the rain-fed regions of Western Kenya.

The optimization process identified the optimum point for the yield of potato tuber to be a saddle point. Ridge analysis method which corresponds to the method of steepest ascent showed that the predicted optimum levels of the factors on the yield of potato tuber

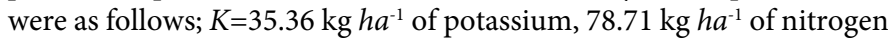

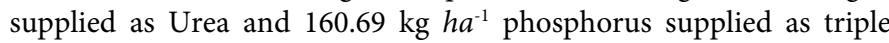
super phosphate (TSP). At this optimum level for the response, one can achieve a potato tuber yield of $29.26 \mathrm{t} \mathrm{ha}$. The current study recommends other researchers to adopt this method since the yield obtained was significantly higher than the current national target which stands at $14.2 \mathrm{t} h a^{-1}$. Finally, the approach applied in this research has been shown to be effective in saving farmers the cost of farm inputs.

\section{Acknowledgements}

The authors would like to thank Mr. Johnson Wambwa and Mr. Silah Shivuli for their cooperation in the laying and management of the experimental plots. I would also not forget the efforts of Mr. Sammy Kiprop, Mr. Moses Some and Mr. Alfred Kurui who were my former students in the applied statistics class who decided to lend me their support during planting season. Also wish to thank Mr. Baraza from MEA for assisting us get some of the fertilizer components.

\section{References}

1. Kirkman MA (2007) Global markets for processed potato products in Vreugdenhil Potato biology and biotechnology advances and perspectives. Elsevier Oxford: 27-44.

2. Khiari L, Parent L, Tremblay N (2001) The $P$ compositional nutrient diagnosis for potato. Agronomy Journal.Vol. 93: 815-819.

3. Temesgen M, Hoogmoed WB, Rockstrom J, Savenije HHG (2009) Conservation tillage implements and systems for smallholder farmers in semi-arid Ethiopia. Soil and Tillage Research 104: 185-191.

4. Kaguongo WP, Gildemacher P, Demo P, Wagoire W, Kinyae P, et al. (2008) Farmer practices and adoption of improved potato varieties in Kenya and Uganda. International Potato center (CIP) Lima Peru. Social Sciences Working Paper 2008, p: 85

5. Box GEP, Hunter JS (1957) Multifactor Experimental Designs for Exploring Response Surfaces. Annals of Mathematical Statistics 28: 195-241.

6. Sampaio FC, Faveri D, Mantovani HC, Lopez Passos FM, Perego P, et al. (2006) Use of response surface methodology for optimization of xylitol production by the new yeast strain Debaryomyces hansenii UFV-170. Journal of Food Engineering 76: 376-386.

7. Roberto M, Solange IR, Rita CLB (2003) Dilute-acid hydrolysis for optimization of xylose recovery from rice straw in a semi-pilot reactor. Industrial Crops and Products 17: 171-176.

8. Morshedi A, Akbarian M (2014) Application of response surface methodology design of experiments and optimization. A mini review Indian Journal of Fundamental and Applied Life Sciences 4: 2434-2439.
9. Myers RH, Montgomery DC, Vining GG, Borror CM, Kowalski SM (2004) Response Surface Methodology A Retrospective and Literature Survey. J Qual Technol 36: 5377 .

10. Quiroz R, Harahagazwe D, Condori B (2014) Potato yield gap analysis in SSA through participatory modeling Optimizing the value of historical breeding tria data. CGIAR Climate Change Agriculture and Food Security (CCFAS); Roots Tubers and Bananas (RTB); Humidtropics, p: 27. Working Paper.

11. Radwan EA, El-Shall ZSA, Ali RAM (2011) Effect of potassium fertilization and humic acid application on plant growth and productivity of potato plants under clay soil. J Plant Production Mansoura University 2: 877-890.

12. Israel Z, Ali Mohammed, Solomon T (2012) Effect of different rates of nitrogen and phosphorus fertilization on Yield and yield component of potato (Solanum tuberosum L.) at Mashan Southwestern of Ethiopia. African Journal of Plant Science 3: 016-024.

13. Rosen CJ, PM Bierman (2008) Potato Yield and Tuber Set as Affected by Phosphorus Fertilization. American Potato Research. 85: 110-120.

14. Jenkins PD, Ali $H$ (2000) Phosphorus supply and progeny tuber numbers in potato crops. AnnApp Biol 136: 41-46.

15. Niguse AM, Fasil K, Eyasu A, (2016) Effect of Potassium on Tuber Yield and Yield Component of Potato (Solanium Tubersum ) on Loamy Soils of AtsbiWenberta Tigray Ethiopia. Journal of Biology Agriculture and Healthcare 6 ISSN 2224-3208.

16. Zelalem A, Tekalign T, Nigussie D (2009) Response of Potato (Solanum tuberosum L.) to Different Rates of Nitrogen and Phosphorus Fertilization on Vertisols at DebreBerhan, in the Central Highlands of Ethiopia. Afr J Plant Sci 3: 16-24.

17. Jamaati-e-Somarin S, Zabihi-e-Mahmoodabad R, Yari A (2010) Yield and yield components of potato (Solanum tuberosum L.) tuber as affected by nitrogen fertilizer and plant density. Australian Journal of Basic and Applied Sciences 4: 3128-3131.

18. Arsenaul WJ, Leblanc DA, Tai GCC, Boswall P (2001) Effect of nitrogen application and seed piece spacing on yield and tuber size distribution in eight potato cultivars. The Potato Association of America General Abstracts Not Presented at the 85th Annual Meeting 78: 301-309.

19. Alam MN, Jahan MS, Ali M.K, Ashraf MA, Islam MK (2007) Effect of vermicompost and chemical fertilizers on growth, yield and yield Components of potato in barind soils of Bangladesh. J Appl Sci Res 3: 1879-1888.

20. Arap Koskei JK (2010) Rotatability and Response Surface Designs of Experiments. Inaugural Lecture 11 Moi University Kenya.

21. Box GBP, Wilson KB (1951) On experimental attainment of optimum conditions Journal of the Royal Statistical Society 13: 1-45.

22. De FaveriD, Torre P, Perego P, Convert A (2004) Statistical investigation on the effects of starting xylose concentration and oxygen mass flow rate on xylitol production from rice straw hydrolyzate by response surface methodology. Journal of Food Engineering 65: 383-9.

23. Dennis KM (2015) Application of Response Surface Methodology for Optimization of Potato Tuber Yield. American Journal of Theoretical and Applied Statistics 4: 300-304.

24. IFA (1992) World Fertilizer Use Manual.Design: Rolf-D. Wuthe, D-6940 Weinheim.

25. MoA (2005) Potato standards in the Crop Production and Livestock Act, Kenya Gazette Supplement no. 38, Nairobi.

26. Rene ER, Jo MS, Kim SH, Park HS (2007) Statistical analysis of main and interaction effects during the removal of BTEX mixtures in batch conditions using wastewater treatment plant sludge microbes. Int J Environ Sci Tech 4 177-182. 